\title{
Herbicide Residues in Soil and Varieties of Rice (Oryza sativa L.) Samples from Borno State, Nigeria
}

\section{Zakari Mohammed, Zaynab Muhammad Chellube, Ayuba Maina Jatau, Joseph Clement Akan*}

Department of Pure and Applied Chemistry, University of Maiduguri, Maiduguri, Borno State, Nigeria

Email address:

joechemakan@yahoo.com (J. C. Akan)

${ }^{*}$ Corresponding author

\section{To cite this article:}

Zakari Mohammed, Zaynab Muhammad Chellube, Ayuba Maina Jatau, Joseph Clement Akan. Herbicide Residues in Soil and Varieties of Rice (Oryza sativa L.) Samples from Borno State, Nigeria. International Journal of Bioorganic Chemistry. Vol. 5, No. 2, 2020 , pp. 15-20. doi: $10.11648 /$ j.jibc.20200502.11

Received: May 8, 2020; Accepted: May 26, 2020; Published: October 26, 2020

\begin{abstract}
The objectives were to determine the concentrations of herbicide residues in soil and different varieties of rice (Oryza sativa L.) and to compare the levels with allowable limits set by WHO/FAO. Four varieties of rice samples (Narica 1, Marica 2, De-gold and Faro 44 were collected from Zabarmari and Bulamari agricultural locations for the determination of herbicide residues. Extraction and cleanup of the samples were carried out using standard analytical procedures. The levels of the studied herbicide residues were determined using Agilent 7890A GC/MS. From the results of the study, it was observed that paraquat and butachlor are the most dominant used herbicides in the study area due to their higher concentrations in the soil and rice samples. The concentrations of all the studied herbicides were significantly higher in the soil samples as compared to the rice samples. The concentrations of all the herbicides in the soil samples were observed to be higher at depth of $0-10 \mathrm{~cm}$, while the lowest concentrations were detected at the depth of $20-30 \mathrm{~cm}$. The study clearly indicates that some of the studied herbicide residues in the rice samples were significantly higher than the WHO and FAO maximum residue limits (MRLs) and acceptable daily intake values (ADIs). Hence, this high values of residues of herbicide call for strict vigilance and constant monitoring in other to protect further contamination of the cultivated rice by herbicides.
\end{abstract}

Keywords: Herbicide, Varieties, Rice, Soil, MRL

\section{Introduction}

Herbicides are substances or cultured biological organisms used to kill or suppress the growth of unwanted plants and vegetation's selectively or non-selectively. Herbicides are in great demand in the domestic market and is widely used in paddy rice fields. It is usually mixed with other pesticides, such as chlomethoxynil, bensulfuron-methyl, oxadiazon, or dymron to make a mixture to be both pre- and postemergence herbicides as well as to inhibit both annual and perennial weeds from growing [1]. The use of herbicides for the control of weed in rice is fast gaining acceptance amongst peasant farmers, having observed that there is increase in the yield of their farm produce when these chemical farm inputs are used. The other side of the herbicides which have to do with their persistence and toxicity is not known by most of the end users. Applications of herbicides for control of weeds releases high levels of residues into the soil and subsequently wash into water bodies used in the cultivation of rice and residues of herbicide have been detected to be persistence in soil by [2-5] and in rice by [4, 6-7]. But cases of internationally herbicides poisoning in human has also been reported and documented by [8-10] for paraquate; [11] for glyphosate. Rice (Oryza sativa L.), a member of family Poaceae and subfamily Oryzoidea, is one of the major staple food consumed by $70 \%$ of the world's population. It occupies one fifth of the total land covered under cereal crops [12]. Rice, which is mainly, consumed as a whole grain supplies $20 \%$ of daily calories for the world population (http://apps.fao.org). The adaptation of rice cultivars to wide climatic conditions has led to the development of thousands of rice varieties having diverse quality features in terms of physical, cooking, eating and product development characteristics.

Zabarmari and Bulamari agricultural areas are primarily agricultural areas with intense herbicide and agrochemical 
usage. Herbicides are extensively used in the area to eliminate weed and enhance the production of rice, vegetables, cereals, and fruits. Rice from Zabarmari and Bulamari Agricultural also constitute an important source of carbohydrate for the inhabitants in and around Borno State and are a major source of income for the inhabitants, However, the agricultural activities have impacted negatively on the soil because bioaccumulation and bio-concentration of the herbicides in the rice are capable of reaching toxic levels even at low exposure. No studies have been carried out in Zabarmari and Bulamari Agricultural areas although herbicides of high toxicity are used to eliminate weeds on the rice farms. Hence, this study is aimed to determine the concentrations of herbicide residues in domestic rice samples cultivated in Zabarmari and Dusuman. The levels of the determine herbicide residues will be compared with allowable limits set by WHO/FAO.

\section{Materials and Methods}

\subsection{Sample Collection}

FARO is the acronym for Federal Agricultural Research Oryza in Nigeria. Faro 40 is a medium-duration variety recommended for most environments in Nigeria. FARO 40, Narica 1 and Marica 2 are composite developed in Nigeria and are resistant to lodging and diseases. According to method adopted by [13]. Rice samples (Narica 1, Marica 1, De-gold and Faro 44) were collected from Zabarmari and Bulamari in Jere Local Government Area, Borno State Nigeria. The different varieties of rice samples were be transported to the Department of Pure and Applied Chemistry Laboratory, University of Maiduguri, and stored at $25^{\circ} \mathrm{C}$ pending analysis. Three soil samples were collected at each sample point and was done at three different depths $(0-5 \mathrm{~cm}$, $5-10 \mathrm{~cm}$ and $10-15 \mathrm{~cm}$ ), by using spiral auger of $2.5 \mathrm{~cm}$ diameter. Soil were randomly sampled and bulked together to form a composite sample. The soil samples were placed in a clean plastic bags and transported to the Department of Pure and Applied Chemistry laboratory, University of Maiduguri. Samples were collected for a period of four months.

\subsection{Extraction of Rice Samples}

The rice samples were extracted in accordance to method described by [14] and adopted by [15]. Twenty grams (20g) of each of the homogenized rice samples was weighed into an Erlenmeyer flask and extracted using $100 \mathrm{ml}$ of acetonitrile by shaking for $30 \mathrm{~min}$ using a reciprocal shaker. The mixture was filtered by vacuum suction pump and the residual cake was washed using $50 \mathrm{ml}$ acetonitrile. The filtrates were combined and made up to $200 \mathrm{ml}$ using acetonitrile.

\subsection{Clean-up of Sample Extracts}

The clean-up of the rice extract was carried out According to method described by [15]. Two milliliter ( $2 \mathrm{mls})$ of aliquot of the acetonitrile extract was cleaned using solid-phase extraction with a styrene-divinylbenzene cartridge. Eight mililitre $(8 \mathrm{mls})$ of water was added to the acetonitrile extract and the mixture was loaded onto the cartridge. The cartridge was washed using $10 \mathrm{ml}$ acetonitrile: water $(1: 4, \mathrm{~V} / \mathrm{v})$ and 15 $\mathrm{ml}$ tetrahydrofuran was passed through the cartridge; the eluate was evaporated to dryness using a rotary evaporator and nitrogen blow down apparatus. The residue was dissolved and diluted using $10 \mathrm{ml}$ of acetonitrile: toluene (3:1, $\mathrm{V} / \mathrm{v})$ and loaded onto a graphite carbon black cartridge (500 $\mathrm{mg} / 6 \mathrm{ml}$, (Superclean ENVI-Carb; Sigma- Aldrich, MO, USA) conditioned with the acetonitrile: toluene mixture). An additional $20 \mathrm{ml}$ of the acetonitrile: toluene mixture was passed twice through the cartridge. All of the eluate was collected in a round-bottom flask and evaporated to dryness using a rotary evaporator and nitrogen blow down apparatus, after which the residue was dissolved and diluted using a suitable volume of acetonitrile: water $(4: 1, \mathrm{~V} / \mathrm{v})$ mixture.

\subsection{Extraction of Herbicide Residues in Soil Samples}

A method described by [16] was used for the extraction of herbicides from soil samples. Soil samples was extracted using a soil-packed bulb column. Each sample (25 g) was weighed into a glass jar, the soil was fortified at this step, before adding pre-cleaned sand (25 g) and granular sodium sulphate $(50 \mathrm{~g})$. The sample mixture was manually shaken for $30 \mathrm{sec}$ and placed on a roller for $30 \mathrm{~s}$ and then allowed to stand for $20 \mathrm{~min}$ to provide time for the sodium sulphate to absorb any residual moisture from the soil. The sample mixture will be transferred to a $250 \mathrm{ml}$ bulb column and the sample jar was triple rinsed with small amounts of $5 \mathrm{ml}$ hexane and transferred to the bulb column. The soil contents were extracted with acetone: hexane $(1: 1 \mathrm{v} / \mathrm{v}, 250 \mathrm{ml}$ mixture $)$ and the eluate collected and concentrated to $100 \mathrm{ml}$ using a rotary evaporator. The soil extract was then be subjected to additional clean-up.

\subsection{Clean-Up of Extract from Soil Samples}

A method by adopted by [16] was used. Clean-up of extract was performed on Florisil cartridges. Florisil cartridges was preconditioned with ethyl acetate and petroleum ether. The cartridges were loaded with $2 \mathrm{~mL}$ petroleum ether extract above. The cartridges was washed with petroleum ether $(2 \mathrm{~mL})$, and discarded. The cartridges was re-washed with $2 \mathrm{ml}$ petroleum etherethyl acetate (98/2, $\mathrm{v} / \mathrm{v})$, and discarded. The analyte was eluted with $2 \mathrm{ml}$ petroleum ether-ethyl acetate $(95 / 5, \mathrm{v} / \mathrm{v})$, and concentrated in a rotary evaporator $\left(40^{\circ} \mathrm{C}\right)$ and completely dried under a nitrogen purge. The residue was re-dissolved with $2 \mathrm{ml}$ methanol for GC/MS analysis.

\subsection{Determination of Herbicide Residues}

Gas chromatography coupled with mass spectrometer SHIMADZU GC/MS with model number (GC-17A), equipped with a fluorescence detector was used determination of herbicide residues. 


\section{Results and Discussion}

\subsection{Atrazine}

The concentrations of atrazine in soil samples in different depth from Zabarnari and Bulamari agricultural locations are as presented in Figures 1 and 2. The levels of atrazine was relatively higher in the soil samples as compared to the rice samples Figures 4 and 5. The highest concentration of 6.55 $\mathrm{mg} / \mathrm{kg}$ atrazine in the soil sample was detected at $0-5 \mathrm{~cm}$ in Zabarmari agricultural location, while the lowest value of 1.45 $\mathrm{mg} / \mathrm{kg}$ was observed at 20-30 $\mathrm{cm}$ depth at Bulamari location. In all the four varieties of rice sample studied, the highest concentration of $1.58 \mathrm{mg} / \mathrm{kg}$ atrazine was detected in De-gold rice samples from Zabarmari, while the least concentration of $0.11 \mathrm{mg} / \mathrm{kg}$ atrazine was observed in faro 44 from Bulamari. The present findings agree with similar findings carried out by [17]. Owing to their values ranging from $0.6-3.0 \mu \mathrm{g} \mathrm{kg}^{-1}$ for ATR to $0.6-1.6 \mu \mathrm{g} \mathrm{kg}^{-1}$ for DEA and $0-0.028 \mathrm{ngkg}^{-1}$ by [18]. Study by [19] revealed the accumulation of atrazine in rice plants led to toxic responses such as over-generation of hydrogen peroxide and superoxide anions. The result of the study also shows that the concentrations of all the study herbicides were higher in the Zabarmari location when compared with Bulamari location. The concentration of atrazine in the studied rice samples were much higher than the WHO and FAO maximum residue limit (MRL) of $0.05 \mathrm{mg} / \mathrm{kg}$, and the acceptable daily intake values (ADIs) of $0.02 \mathrm{mg} / \mathrm{kg}$.

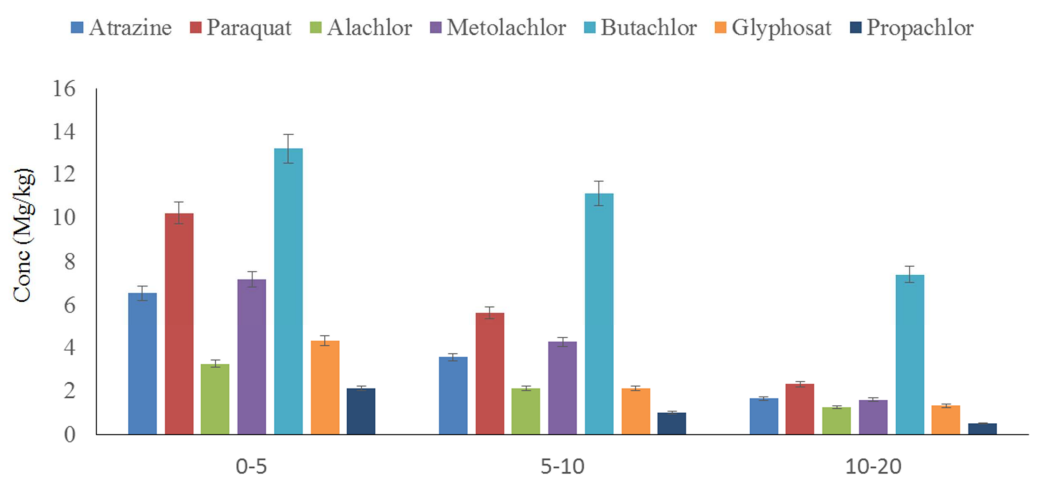

Figure 1. Mean Cconcentration of Herbicide residues in Different Depth from Zabarmari Agricultural Location.

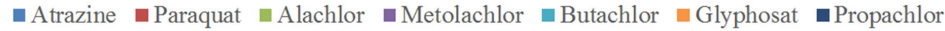

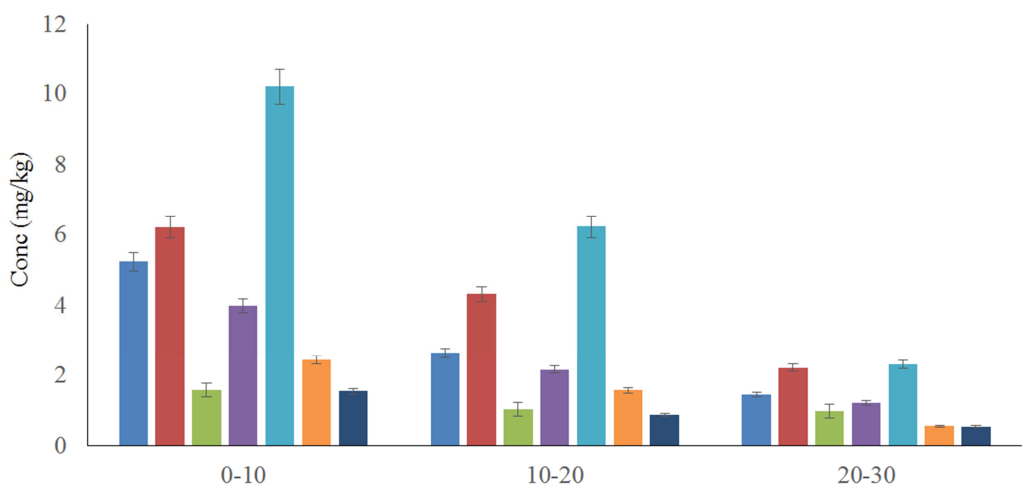

Figure 2. Mean Cconcentration of Herbicide residues in Different Depth from Bulamari Agricultural Location.

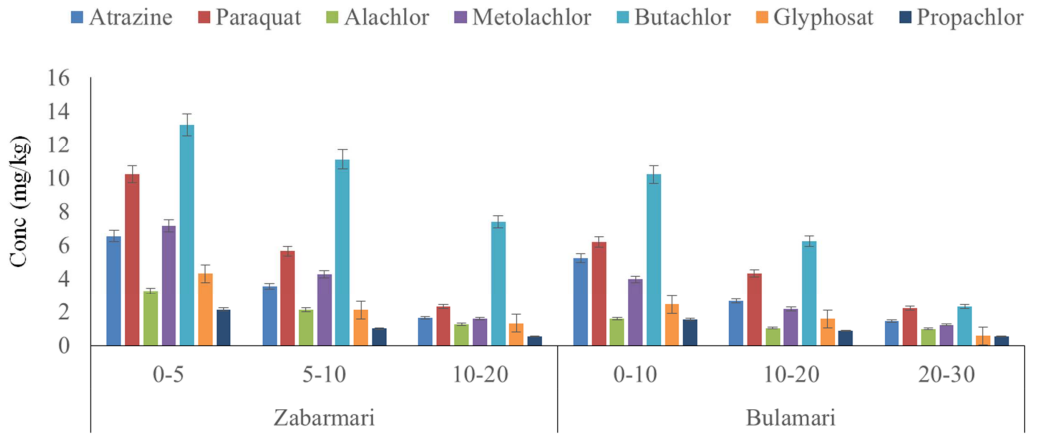

Figure 3. Comparison in Concentrations of Heavy metals bteween Zabarmari and Bulamari Agricultural Location. 


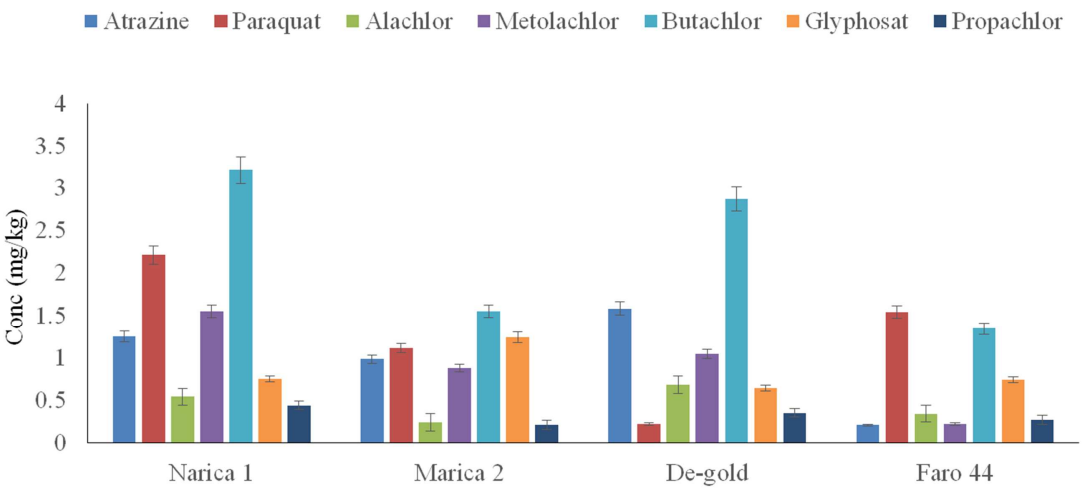

Figure 4. Mean Concentrations of Heavy Metals in different Varieties of rice in Zabarmari Agricultural location.

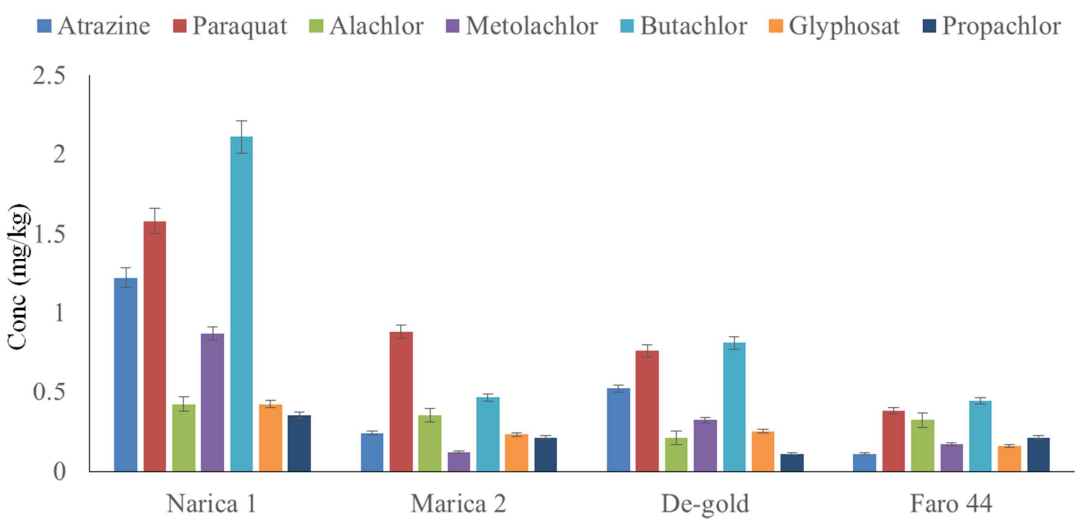

Figure 5. Mean Concentrations of Heavy Metals in different Varieties of rice in Bulamari Agricultural location.

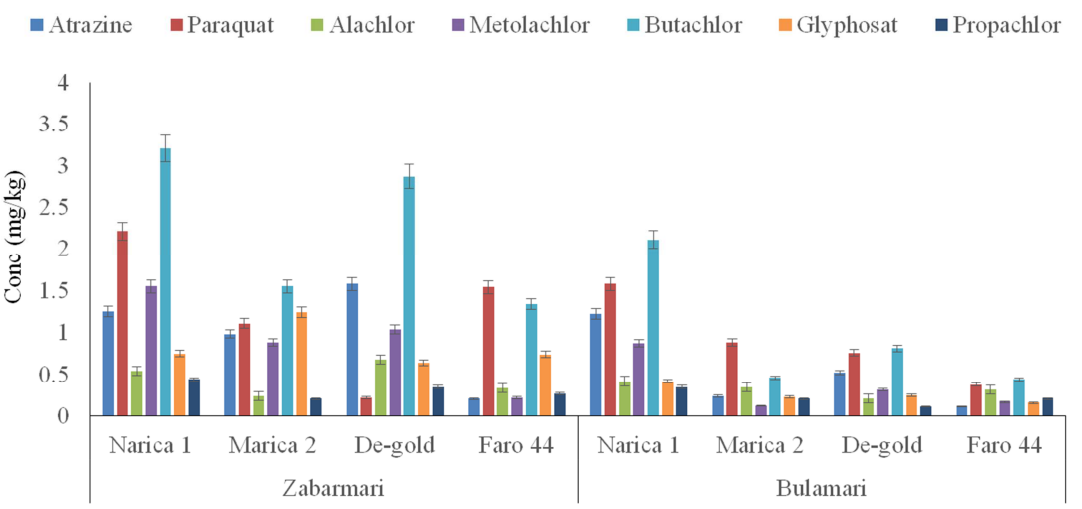

Figure 6. Comparison in Concentrations of Heavy Metals in Different varieties of rice between Zabarmari and Bulamari Agricultural locations.

\subsection{Paraquat}

The highest level of paraquat was recorded in the soil samples from Zabarmari location with a value of 10.23 $\mathrm{mg} / \mathrm{kg}$, while the lowest value was recorded in the soil samples from Bulamari location with a value of $2.22 \mathrm{mg} / \mathrm{kg}$ Figures 1 and 2. It was also observed that the concentration of paraquat in the soil samples were relatively higher at a depth of 0-5 cm, while 10-15 cm depth shows the lowest values in both study areas. The values of paraquat in soil were much well lower than value of $34.98 \mathrm{mg} / \mathrm{kg}$ as reported by [20] of $34.98 \mathrm{mg} / \mathrm{kg}$. Among the four varieties of rice sample studied, the highest concentration of $2.21 \mathrm{mg} / \mathrm{kg}$ paraquat was detected in Narica1, while the minimum concentration of $0.22 \mathrm{mg} / \mathrm{kg}$ paraquat was observed in De- gold Figure 5. Relatively, the levels of paraquat was observed to be highest in Zabarmari location as compared with Bulamari Location. [21] determined paraquat in rice samples with values of $0.267,0.261,0.24 \mathrm{mg} / \mathrm{kg}$. The concentration of paraquat in all the varieties of rice samples were much higher than the WHO and FAO maximum residue limit (MRL) of $0.5 \mathrm{mg} / \mathrm{kg}$, with exception of De-gold from Zabarmari location and Faro 44 from Bulamari location, and also higher than the acceptable daily intake values (ADIs) of $0.005 \mathrm{mg} / \mathrm{kg}$.

\subsection{Alachlor}

Findings from the present study showed that the concentration of alachlor is relatively higher in the soil 
samples as compared to rice samples Figures 1, 2, 4 and 5. The highest concentration of $3.26 \mathrm{mg} / \mathrm{kg}$ alachlor in the soil sample was detected at Zabarmari location, while the lowest value of $0.98 \mathrm{mg} / \mathrm{kg}$ was observed in the Bulamari location. From the two agricultural locations, it was also observed that the concentration of alachlor in the soil samples were relatively higher at a depth of 0-5 cm, while 10-15 cm depth shows the lowest values. Results from the four varieties of rice samples studied shows that the concentration of $0.68 \mathrm{mg} / \mathrm{kg}$ alachlor was detected in De-gold rice samples, while the total minimum concentration of $0.21 \mathrm{mg} / \mathrm{kg}$ alachlor was detected in De-gold samples from Bulamari location. Similar finding was carried out by [22] with values of alachlor ranging from $0.146-0.355 \mathrm{mg} / \mathrm{kg}$. The concentration of alachlor in all the rice samples was higher than the WHO and FAO maximum residue limit (MRL) $0.2 \mathrm{mg} / \mathrm{kg}$, and the acceptable daily intake value (ADI) of $0.01 \mathrm{mg} / \mathrm{kgbw}$.

\subsection{Metolachlor}

The highest level of metolachlor in the soil samples was recorded from Zabarmari location with a value of $7.17 \mathrm{mg} / \mathrm{kg}$, while the least value was recorded in the soil samples from Bulamari location with a value of $1.22 \mathrm{mg} / \mathrm{kg}$ Figures 1 and 2 . The results further shows that the concentration of metolachlor in the soil samples was relatively higher at a depth of $0-5 \mathrm{~cm}$, while $10-15 \mathrm{~cm}$ depth shows the lowest values Figure 3. Findings from the rice samples shows that the maximum concentration of $1.55 \mathrm{mg} / \mathrm{kg}$ metolachlor was detected in Narica 1, while the minimum concentration of $0.12 \mathrm{mg} / \mathrm{kg}$ metolachlor was observed in Marica 2 samples. The values of metolachlor in rice samples were like values detected in a study carried out by [23]. The concentration of metolachlor in the four varieties of rice samples were higher than the WHO and FAO maximum residue limit (MRL) of $0.05 \mathrm{mg} / \mathrm{kg}$ and the acceptable daily intake values (ADIs) of $0.1 \mathrm{mg} / \mathrm{kg}$.

\subsection{Butachlor}

The highest level of butachlor in the soil samples was observed at the Zabarmari location with a value of 13.22 $\mathrm{mg} / \mathrm{kg}$ Figure 1, while Bulamari shows the lowest concentration of $2.31 \mathrm{mg} / \mathrm{kg}$ Figure 2. The highest concentration of $3.21 \mathrm{mg} / \mathrm{kg}$ butachlor in the rice samples was detected in Narica 1 Figure 4, while Bulamari sample location shows the lowest concentration of $0.44 \mathrm{mg} / \mathrm{kg}$ butachlor Figure 5. These results of the present study are relatively higher than the study carried out by [24] which indicate a concentration range of 0.012 and $0.007 \mathrm{mg} / \mathrm{kg}$ in rice grains and straw after treatment with butachlor at 2.0 $\mathrm{kg} / \mathrm{ha}$ rate. The concentration of butachlor in the soil samples were found to be higher than the findings carried out by [2526]. The adverse health effects of butachlor on human includes weight loss, weight changes in internal organs, reduced brain size together with lesions. The concentration of butachlor in all the soil and rice samples were higher than the WHO and FAO maximum residue limit (MRL) of $0.1 \mathrm{mg} / \mathrm{kg}$.

\subsection{Glyphosate}

Glyphosate was relatively higher in the soil samples as compared to rice samples. The highest concentration of $4.32 \mathrm{mg} / \mathrm{kg}$ in the soil sample was detected Zabarmari location, while the lowest value of $056 \mathrm{mg} / \mathrm{kg}$ was observed in the Bulamari location Figure 3. It was also observed that the concentration of glyphosate in the soil samples were relatively higher at a depth of 0-5 cm, while 10-15 cm depth shows the lowest values Figure 3 . The maximum concentration of 0.75 $\mathrm{mg} / \mathrm{kg}$ glyphosate was detected in Narica1, while the minimum concentration of $0.16 \mathrm{mg} / \mathrm{kg}$ glyphosate was observed in Faro 44 Figure 6 . The concentration of glyphosate in all the rice samples were lower than the WHO and FAO maximum residue limit (MRL) of $2.0 \mathrm{mg} / \mathrm{kg}$ and the acceptable daily intake value (ADI) of $1.0 \mathrm{mg} / \mathrm{kgbw}$.

\subsection{Propachlor}

The highest level of propachlor in soil samples was recorded in at the Zabarmari location with a value of 2.13 $\mathrm{mg} / \mathrm{kg}$, while the least value was recorded at Bulamari location with a value of $0.55 \mathrm{mg} / \mathrm{kg}$. The highest concentration of $0.44 \mathrm{mg} / \mathrm{kg}$ propachlor was detected in Narica 1, while De-gold shows the lowest concentration of $0.11 \mathrm{mg} / \mathrm{kg}$ Figures 4 and 5 .

\section{Conclusion}

Results of the present study showed that the rice samples contained high levels of herbicide residues, the study also revealed that butachlor was the most dominant herbicides in the two agricultural locations, followed by paraquate. The concentrations of all the herbicides in the soil samples were observed to be higher at depth of $0-5 \mathrm{~cm}$, while the lowest concentrations were detected at the depth of $10-15 \mathrm{~cm}$. The study also revealed that the studied herbicide residues were significantly higher than the WHO and FAO maximum residue limits (MRLs) and acceptable daily intake values (ADIs) values. Hence, the is a need for intervention by relevant agencies of Government to educate farmers within the study areas of the needs to reduce the indiscriminate use of these chemicals for plant control.

\section{Acknowledgements}

Authors gratefully thank the full financial support from TetFund (Tertiary Educational Trust Fund, Nigeria) through University of Maiduguri Management (Tetfund/DESS/UNI/ MAIDUGURI/RP/VOL.V).

\section{References}

[1] Su-hsiang, T., Pi-chiou, C. and Shin-shou, C. (2002). Determination of Butachlor and Pencycuron Residues in Vegetables and Rice: Application of the Macroporous Diatomaceous Earth Column. Journal of Food and Drug Analysis, 10 (2): 127-134. 
[2] Shobha, S. (2014). Herbicides residues in soil, water, plants and non-targeted organisms and human health implications: an Indian perspective. Indian Journal of Weed Science, 46 (1): 66-85.

[3] Nag, S. K. and Das, S. K. (2009). Persistence of atrazine in soil under fodder sorghum. Journal of Crop and Weed, 5 (2): 131-135.

[4] Sondhia, S., Singh, V. P. and Yaduraju, N. T. (2006). Persistence of butachlor in sandy clay loam soil and its residues in rice grains and straw. Annals of Plant Protection Sciences, 14 (1): 206-209.

[5] Sanyal, D. and Kulshrestha, G. (2003). Degradation of metolachlor in soil inoculated with a mixed fungal culture. Biology and Fertility of Soils, 38 (4): 253-256.

[6] Reddy, K. N., Rao, B. N., Sultan, M. A., Reddy, D. J. and Babu, T. R. (1998). Residues of butachlor in paddy. Journal of Research ANGRAU, 26 (3-4): 48-49.

[7] Sondhia, S. and Dixit, A. (2012). Bioefficacy and persistence of ethoxysulfuron in rice. ORYZA-An International Journal on Rice, 49 (3): 178-182.

[8] Attar, N. R, Arsekar, and Pawar, M. N. (2009). Paraquat poisoning - A deadly poison: A case report. Vilas Chavan MedicoLegal, 9 (2): 43-47.

[9] Khosya, S. and Gothwal, S. (2012). Two cases of paraquat poisoning from kota, Rajasthan, India case reports in critical care. ID 652146. DOI. 10.1155/2012/652146.

[10] Kondle, R., Vidavalur, M., Parri, S., Polam, R. R., Vajja, V. and Agrawal, A. (2013). Paraquat poisoning: A case report and review of literature. Case Report 20 (3): 198-200.

[11] Das, S. K., Anand, P. R., Vijaya, K. V. and Ponnusankar, S. (2012). Title NSHM Journal of Pharmacy and Healthcare Management 3: 112-115.

[12] Chakravarthi, B. K. and Naravaneni, R. (2006). SSR marker based DNA fingerprinting and diversity study in rice (Oryza sativa). PBR Laboratories, Researchgate Publications.

[13] Akan, J. C., Dawa, J. Y., Inuwa, L. B. and Zakari, M. (2018). Polycyclic aromatic hydrocarbons in different varieties of rice (oryza Sativa) from Yobe State, Nigeria. Eviromental and Pollution. 7 (2): 1927-0909.

[14] Cho, S. K., Abd, E. A., Jeon, H. R., Choi, J. H., Shin, H. C. and Shim, J. H. (2007). Comparison of Different Extraction Methods for the Simultaneous Determination of Pesticide Residues in Kiwi Fruit Using Gas Chromatography-Mass Spectrometry. Journal of Biomedical and Chromatography, 22: 727-735.

[15] Akan, J. C., Musa, M. Mahmud., Maimuna Waziri. and Zakari, Mohammed. (2015). Residues of Organchlorine Pesticide in
Watermelon (Citrulus lanatus) and Soil Samples from Gashua Bade Local Government Area Yobe State, Nigeria. Advances in Analytical Chemistry, 5: (3): 61-68.

[16] Anastassiades, M., Lehotay, S. J., Stajnbaher, D. and Schenck, F. J. (2003). Fast and easy multiresidue method employing acetonitrile extraction, partitioning and dispersive solid phase extraction for the determination of pesticides residues in produce. Journal of AOAC International, 86 (2): 412-431.

[17] Shuxuan, L., Xinfeng, D. Ming, S. and Hanwen, S. (2016). Analysis of herbicide atrazine and its degradation products in cereals by ultra-performance liquid chromatography-mass spectrometry. Anal. Methods, 83599-3604.

[18] Tariq, M., Bushra1, S., Mansoor-ul-H., Maqbool, U., M. R. Asi, M. R., Gulzar, A. and Iqbal, M. F. (2015). Residual estimation of isoproturon, atrazine and grain protectants instored wheat grains. International Journal of Advances in Biology, 2 (3).

[19] Jia, J. Z., Yi. C. L., Jin. J. Z., Li, R. T. and Hong, Y. (2014). Accumulation and toxicological response of atrazine in rice crops. Ecotoxicology and Environmental Safety, 102: 105-112.

[20] Janaki. P., Archana, M. and Priya, S. R. (2017). Effect of herbicides on potato and their persistence in acid soil under semiarid tropical condition. Advances in Plants \& Agriculture Research, 7 (3): 272-277. DOI: 10.15406/apar.2017.07.00254.

[21] Ionara, R. P., Giovana, M. E., Velaa, A. K., Jos, M. S., Jonatan, V. D., Carmem, D. C., Germani, C. and Rafael, V. (2016). Determination of paraquat and diquat: LC-MS method optimization and validation. Food Chemistry, 209: 248-255.

[22] Al-Zahraa, M. D., Soumia, M. D. and Fathy, E. E. (2016). Analysis of Organochlorine and Organophosphorus Pesticide Residues in Dairy Products and Baby Foods from Egyptian Markets. J. Environ. Anal. Toxicol. 6: 412. doi: 10.4172/21610525.1000412 .

[23] Michael, P. B., Terry, L. L. and Ronald, E. T. (1985). Metolachlor Effects of Metolachlor Residues on Rice (Oryza sativa). Weed Science, 33 (6): 819-824.

[24] Deka, S. K and Gogoi A. K. (1993). Studies on the persistence of butachlor in soil and residue in straw and grain of rice (Oryza sativa L.) pp. 96-98. In: Integrated weed management for sustainable agriculture. Proceedings of an Indian Society of Weed Science International Symposium, Hisar, India, 18-20 November 1993, Vol. II.

[25] Devi, M. P., Reddy, C. N and Reddy, N. V. (1998). Crop tolerance studies tooxyfluorfen and its persistence in soil. Indian Journal of Weed Science, 30 (3-4): 214-215.

[26] Jayakumar, R. and Sankaran, S. (1995). Evaluation of anilofos 50 EC residues in transplanted rice. Madras Agricultural Journal, 82 (4): 296-298. 